\title{
Separation of Cobalt and Nickel with 2-Ethylhexyl Phosphonic Acid Mono-2-Ethylhexyl Ester Using a Countercurrent Mixer-Settler Cascade
}

\author{
Teppei WATARI, Daiki TAKASE, Syouhei NISHIHAMA* and Kazuharu YOSHIZUKA \\ Department of Chemical Engineering, The University of Kitakyushu, Hibikino 1-1, Kitakyushu 808-0135, \\ Japan
}

(Received December 27, 2016; Accepted February 2, 2017)

\begin{abstract}
Separation of cobalt and nickel was investigated using a 4-stage countercurrent mixer-settler cascade, employing 2-ethylhexyl phosphonic acid mono-2-ethylhexyl ester as the extractant. Extraction equilibrium formulations were established up to high loading ratios and extraction constants were determined, based on a batch extraction system in both single metal and binary metal systems. The separation of cobalt and nickel was then carried out using the 4-stage countercurrent mixer-settler cascade. Selective extraction of cobalt was achieved by the extraction step, while a small amount of nickel was also extracted. Nickel in the organic solution was removed by scrubbing with the solution containing the metals, while the recovery of cobalt was decreased. The concentration profiles of the metals with the countercurrent mixer-settler cascade were calculated based on the determined extraction equilibrium formulations and the material balance, although the calculation diverged when the $\mathrm{pH}$ was high especially at the 4th stage.
\end{abstract}

\section{Introduction}

Solvent extraction has been widely used as a process for separation, purification, and recovery of critical metals, due to its simplicity of equipment and operation. Separation of cobalt and nickel by solvent extraction has been one of the critical issues, and much work has been reported previously [1-5]. Separation of the metals is however still an active issue in recent years, because the metals are included in the cathode material of lithium ion batteries. Indeed, solvent extraction techniques have been applied for the recovery of the metals from spent lithium ion batteries [6-8], and these techniques are presented in a review article [9]. Based on previous literature, 2-ethylhexyl phosphonic acid mono-2-ethylhexyl ester (PC-88A) is one of the feasible extractants for the separation of cobalt from nickel.

When solvent extraction is applied in an industrial scale operation, countercurrent mixer-settler cascades are generally used. Previously, simulation work for the construction of separation processes of metals using countercurrent mixer-settler cascades has been investigated based on extraction equilibrium formulations and materials balance [10-12]. Extraction equilibria of the metals up to high loadings on the extractant are important to the application of the formulations for the simulation work. The extraction equilibria for cobalt and nickel up to high loadings therefore should be investigated, since almost all extraction equilibrium formulations reported for the metals are based on the slope analysis method and thus 
are limited to low loadings. Thakur et al. have reported a mathematical model for the separation of cobalt, nickel, and copper with a countercurrent mixer-settler cascade [13]. The model was however based on a fixed concentration of PC-88A at $0.5 \mathrm{~mol} / \mathrm{L}$, and was not based on the extraction equilibrium formulations, which cannot be used when the extractant concentration is changed.

In the present work, therefore, separation of cobalt and nickel using a countercurrent mixer-settler cascade was investigated, employing PC-88A as the extractant. Extraction equilibria of the metals up to high loading ratios were first investigated in both single metal and binary metal systems. Separation of the metals was then carried out using a 4-stage countercurrent mixer-settler cascade. The results obtained were compared with the simulation work based on the extraction equilibrium formulations and material balances. Scrubbing of the organic phase after extraction was also carried out using the mixer-settler cascade to purify cobalt in the organic phase.

\section{Experimental}

\subsection{Reagents}

PC-88A was supplied by Daihachi Chemical Industry Co. and Exxsol D130 was supplied by Exxon Mobil Co. Exxsol D130 is a petroleum-based low aromatic and low odor hydrocarbon solvent, which mainly includes normal- and iso-alkanes and cyclic hydrocarbons as described in the Exxon Mobil product safety summary. All other reagents were supplied by Wako Pure Chemical Industries, as analytical-grade reagents. Aqueous solutions of cobalt and/or nickel were prepared by dissolving their sulfates into deionized water, and the $\mathrm{pH}$ values were adjusted with sulfuric acid and sodium hydroxide solutions for the batch extractions or with 4-(2-hydroxyethyl)-1-piperazineethanesulfonic acid (HEPES) for the mixer-settler cascade system. Preliminary experiments revealed that extraction of cobalt and nickel was not affected by HEPES. The organic solutions were prepared by dissolving PC-88A in Exxsol D130, and the concentration of PC-88A was determined by a potentiometric titration method.

\subsection{Batch extraction of cobalt and nickel}

Organic and aqueous solutions having an $\mathrm{O} / \mathrm{A}$ volume ratio of 1 were shaken by a mechanical shaker in a thermostat bath (Taitec ML-10F) for more than $1 \mathrm{~h}$ at $298 \mathrm{~K}$. Weighed organic samples were stripped with $3 \mathrm{~mol} / \mathrm{L}$ sulfuric acid at an $\mathrm{O} / \mathrm{A}$ volume ratio of 0.5 . The resulting samples were analyzed by using an inductively coupled plasma atomic emission spectrophotometer (ICP-AES; Shimadzu ICPS7000 or Shimadzu ICPE-9000). The aqueous phase $\mathrm{pH}$ value was measured with a $\mathrm{pH}$ meter (Horiba F-23). The loading ratio is defined as the concentration of the metal extracted to that

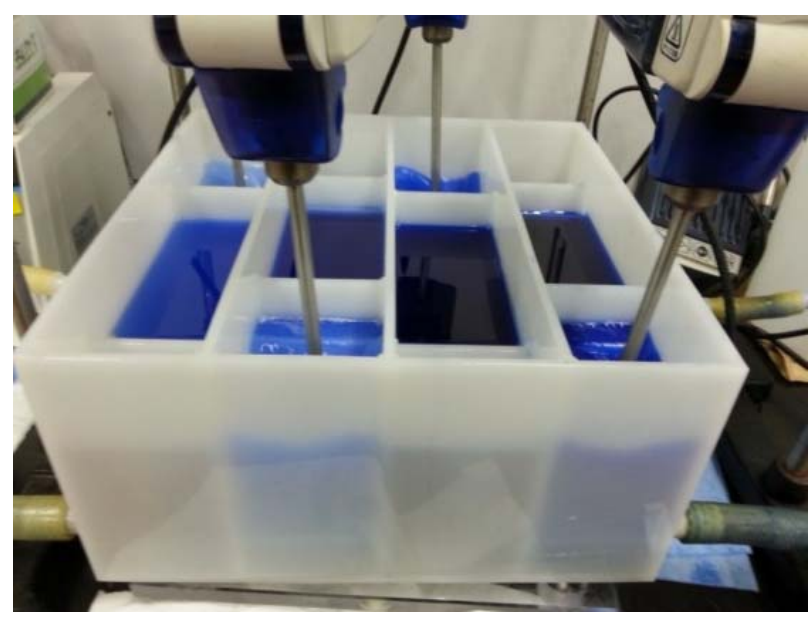

Figure 1. Image of 4-stages countercurrent mixer-settler cascade. 
of the feed PC-88A concentration as dimeric species $\left([\overline{\mathrm{M}}] /\left[\overline{(\mathrm{RH})_{2}}\right]_{\text {feed }}\right)$. The bars indicate species in the organic phase. In the case of scrubbing, the organic solution loaded with the two metals was contacted with a dilute sulfuric acid solution without metals, and the two phases were shaken for more than $1 \mathrm{~h}$ at $298 \mathrm{~K}$. The nonlinear least square method for determination of the extraction equilibrium constants was carried out using Basic/98 (version 5, Dennougumi) installed on a PC with Windows 10 as the operating system.

\subsection{Separation of cobalt and nickel with a 4-stage countercurrent mixer-settler cascade}

A countercurrent mixer-settler cascade, having $0.5 \mathrm{~L}$ mixers and $1.4 \mathrm{~L}$ settlers, was used for the separation of the metals, as shown in Figure 1. The PC-88A/D130 solution of $\left[\overline{(\mathrm{RH})_{2}}\right]_{\text {feed }}=0.5 \mathrm{~mol} / \mathrm{L}$ was fed to the 1st stage and the aqueous solution containing cobalt and nickel of ca. $0.2 \mathrm{~g} / \mathrm{L}$ was fed to the 4 th stage. Each solution was fed at $90.7 \mathrm{~mL} / \mathrm{min}$ by a peristaltic pump, and all the mixers were stirred at $500 \mathrm{rpm}$. The $\mathrm{O} / \mathrm{A}$ volume ratio at each stage was kept at 1 . After starting to feed both solutions and to stir the mixers, the $\mathrm{pH}$ value of the aqueous solution from the outlet of the cascade was checked, and the mixer-settler cascade was judged to have reached steady-state when the $\mathrm{pH}$ value became stable. After steady-state, the aqueous and organic solutions at each stage were sampled. The organic solutions were stripped with $3 \mathrm{~mol} / \mathrm{L}$ sulfuric acid at an O/A volume ratio of 0.5 . The resulting samples were analyzed with ICP-AES. The concentration profile of the countercurrent mixer-settler cascade was calculated by Basic/98 [10-12].

\section{Results and Discussion}

\subsection{Extraction equilibrium at high loading ratio of the organic phase}

Extraction of cobalt and nickel with PC-88A at low loading ratio of organic phase has been widely investigated by the slope analysis method, and reported as Eqs. (1) and (2) [2].

$$
\begin{aligned}
& \mathrm{Co}^{2+}+2 \overline{(\mathrm{RH})_{2}} \rightleftarrows \overline{\mathrm{CoR}_{2}(\mathrm{RH})_{2}}+2 \mathrm{H}^{+} ; K_{\mathrm{ex} 1, \mathrm{co}} \\
& \mathrm{Ni}^{2+}+3 \overline{(\mathrm{RH})_{2}} \rightleftarrows \overline{\mathrm{NiR}_{2}(\mathrm{RH})_{4}}+2 \mathrm{H}^{+} ; K_{\mathrm{ex} 1, \mathrm{Ni}}
\end{aligned}
$$
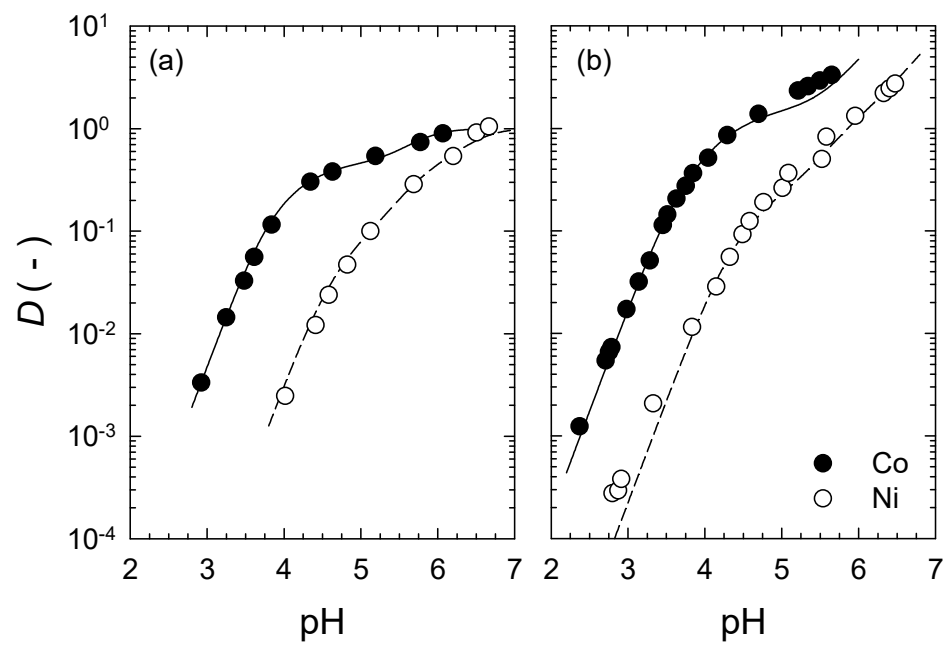

Figure 2. Effect of equilibrium $\mathrm{pH}$ on the distribution ratios of cobalt and nickel. (a) $\left[\overline{(\mathrm{RH})_{2}}\right]_{\text {feed }}=4.98 \times$ $10^{-2} \mathrm{~mol} / \mathrm{L}$ and (b) $\left[\overline{(\mathrm{RH})_{2}}\right]_{\text {feed }}=9.47 \times 10^{-2} \mathrm{~mol} / \mathrm{L},[\mathrm{Co}]_{\text {feed }}=9.91 \times 10^{-2} \mathrm{~mol} / \mathrm{L}$, and $[\mathrm{Ni}]_{\text {feed }}=9.83 \times 10^{-2}$ $\mathrm{mol} / \mathrm{L}$. Calculated distribution ratios are shown by the lines. 
Extraction of the metals at a high loading ratio of the organic phase was carried out. The distribution ratios obtained in each single metal system are plotted against the equilibrium $\mathrm{pH}$ values in Figure 2. It is well known the extracted species of the metal at low loading ratio and extractant form aggregates at high loading. For both metals, the loading ratios approached a maximum loading ratio of 1.0, suggesting that a complex containing the dimeric extractant and the metal with a mole ratio of $1: 1$ is formed. When the extracted species at high loading ratio is assumed to form by aggregation of the metal and the extractant with the extracted species at low loading ratio, the extraction equilibrium formulations of cobalt and nickel can be expresses as Eqs. (3) and (4) and Eqs. (5) and (6), respectively.

$$
\begin{aligned}
& \mathrm{Co}^{2+}+\overline{\mathrm{CoR}_{2}(\mathrm{RH})_{2}}+\overline{(\mathrm{RH})_{2}} \rightleftarrows \overline{\mathrm{Co}_{2} \mathrm{R}_{4}(\mathrm{RH})_{2}}+2 \mathrm{H}^{+} ; K_{\mathrm{ex} 2, \text { co }} \\
& \mathrm{Co}^{2+}+\overline{\mathrm{Co}_{2} \mathrm{R}_{4}(\mathrm{RH})_{2}} \rightleftarrows \overline{\mathrm{Co}_{3} \mathrm{R}_{6}}+2 \mathrm{H}^{+} ; K_{\mathrm{ex} 3, \mathrm{co}} \\
& \mathrm{Ni}^{2+}+\overline{\mathrm{NiR}_{2}(\mathrm{RH})_{4}} \rightleftarrows \overline{\mathrm{Ni}_{2} \mathrm{R}_{4}(\mathrm{RH})_{2}}+2 \mathrm{H}^{+} ; K_{\mathrm{ex} 2, \mathrm{Ni}} \\
& \mathrm{Ni}^{2+}+\overline{\mathrm{Ni}_{2} \mathrm{R}_{4}(\mathrm{RH})_{2}} \rightleftarrows \overline{\mathrm{Ni}_{3} \mathrm{R}_{6}}+2 \mathrm{H}^{+} ; K_{\mathrm{ex} 3, \mathrm{Ni}}
\end{aligned}
$$

In the case of cobalt, the total concentration of cobalt in the organic phase and the total concentration of the extractant can be expresses as Eqs. (7) and (8).

$$
\begin{aligned}
& {[\overline{\mathrm{Co}}]_{\text {total }}=\left[\overline{\mathrm{CoR}_{2}(\mathrm{RH})_{4}}\right]+2\left[\overline{\mathrm{Co}_{2} \mathrm{R}_{4}(\mathrm{RH})_{2}}\right]+3\left[\overline{\mathrm{Co}_{3} \mathrm{R}_{6}}\right]} \\
& =K_{\mathrm{ex} 1, \mathrm{Co}}\left[\mathrm{Co}^{2+}\right]\left[\overline{(\mathrm{RH})_{2}}\right]^{2} /\left[\mathrm{H}^{+}\right]^{2}+2 K_{\mathrm{ex} 1, \mathrm{Co}} K_{\mathrm{ex} 2, \mathrm{Co}}\left[\mathrm{Co}^{2+}\right]^{2}\left[\overline{(\mathrm{RH})_{2}}\right]^{3} /\left[\mathrm{H}^{+}\right]^{4} \\
& +3 K_{\mathrm{ex} 1, \mathrm{Co}} K_{\mathrm{ex} 2, \mathrm{Co}} K_{\mathrm{ex} 3, \mathrm{Co}_{\mathrm{o}}}\left[\mathrm{Co}^{2+}\right]^{3}\left[\overline{(\mathrm{RH})_{2}}\right]^{3} /\left[\mathrm{H}^{+}\right]^{6} \\
& {\left[\overline{(\mathrm{RH})_{2}}\right]_{\text {total }}=\left[\overline{(\mathrm{RH})_{2}}\right]+2\left[\overline{\mathrm{CoR}_{2}(\mathrm{RH})_{4}}\right]+3\left[\overline{\mathrm{Co}_{2} \mathrm{R}_{4}(\mathrm{RH})_{2}}\right]+3\left[\overline{\mathrm{Co}_{3} \mathrm{R}_{6}}\right]} \\
& =\left[\overline{(\mathrm{RH})_{2}}\right]+2 K_{\mathrm{ex}, \mathrm{Co}}\left[\mathrm{Co}^{2+}\right]\left[\overline{(\mathrm{RH})_{2}}\right]^{2} /\left[\mathrm{H}^{+}\right]^{2} \\
& +3 K_{\mathrm{ex} 1, \mathrm{Co}} K_{\mathrm{ex} 2, \mathrm{Co}}\left[\mathrm{Co}^{2+}\right]^{2}\left[\overline{(\mathrm{RH})_{2}}\right]^{3} /\left[\mathrm{H}^{+}\right]^{4} \\
& +3 K_{\mathrm{ex} 1, \mathrm{Co}} K_{\mathrm{ex} 2, \mathrm{Co}} K_{\mathrm{ex} 3, \mathrm{Co}}\left[\mathrm{Co}^{2+}\right]^{3}\left[\overline{(\mathrm{RH})_{2}}\right]^{3} /\left[\mathrm{H}^{+}\right]^{6}
\end{aligned}
$$

In the case of nickel, the total concentration of nickel in the organic phase and the total concentration of the extractant can be expresses as Eqs. (9) and (10).

$$
\begin{aligned}
{[\overline{\mathrm{Ni}}]_{\text {total }}=} & {\left[\overline{\mathrm{NiR}_{2}(\mathrm{RH})_{4}}\right]+2\left[\overline{\mathrm{Ni}_{2} \mathrm{R}_{4}(\mathrm{RH})_{2}}\right]+3\left[\overline{\mathrm{Ni}_{3} \mathrm{R}_{6}}\right] } \\
= & K_{\mathrm{ex} 1, \mathrm{Ni}}\left[\mathrm{Ni}^{2+}\right]\left[\overline{(\mathrm{RH})_{2}}\right]^{3} /\left[\mathrm{H}^{+}\right]^{2}+2 K_{\mathrm{ex} 1, \mathrm{Ni}} K_{\mathrm{ex} 2, \mathrm{Ni}}\left[\mathrm{Ni}^{2+}\right]^{2}\left[\overline{(\mathrm{RH})_{2}}\right]^{3} /\left[\mathrm{H}^{+}\right]^{4} \\
+ & 3 K_{\mathrm{ex} 1, \mathrm{Ni}} K_{\mathrm{ex} 2, \mathrm{Ni}} K_{\mathrm{ex} 3, \mathrm{Ni}}\left[\mathrm{Ni}^{2+}\right]^{3}\left[\overline{(\mathrm{RH})_{2}}\right]^{3} /\left[\mathrm{H}^{+}\right]^{6} \\
{\left[\overline{(\mathrm{RH})_{2}}\right]_{\text {total }}=} & {\left.\left.\left[\overline{(\mathrm{RH})_{2}}\right]+3 \overline{\mathrm{NiR}_{2}(\mathrm{RH})_{4}}\right]+3 \overline{\mathrm{Ni}_{2} \mathrm{R}_{4}(\mathrm{RH})_{2}}\right]+3\left[\overline{\mathrm{Ni}_{3} \mathrm{R}_{6}}\right] } \\
= & {\left[\overline{(\mathrm{RH})_{2}}\right]+3 K_{\text {ex } 1, \mathrm{Ni}}\left[\mathrm{Ni}^{2+}\right]\left[\overline{(\mathrm{RH})_{2}}\right]^{3} /\left[\mathrm{H}^{+}\right]^{2} } \\
& +3 K_{\mathrm{ex} 1, \mathrm{Ni}} K_{\mathrm{ex} 2, \mathrm{Ni}}\left[\mathrm{Ni}^{2+}\right]^{2}\left[\overline{(\mathrm{RH})_{2}}\right]^{3} /\left[\mathrm{H}^{+}\right]^{4} \\
& \left.+3 K_{\mathrm{ex} 1, \mathrm{Ni}} K_{\mathrm{ex} 2, \mathrm{Ni}} K_{\mathrm{ex} 3, \mathrm{Ni}}\left[\mathrm{Ni}^{2+}\right]^{3} \overline{(\mathrm{RH})_{2}}\right]^{3} /\left[\mathrm{H}^{+}\right]^{6}
\end{aligned}
$$

Table 1. Extraction constants of cobalt and nickel.

\begin{tabular}{c|c|c|c}
\hline & $K_{\text {ex } 1}$ & $K_{\text {ex2 }}$ & $K_{\text {ex3 }}$ \\
\hline $\mathrm{Co}$ & $1.95 \times 10^{-5}$ & $2.39 \times 10^{-6}$ & $9.87 \times 10^{-11}$ \\
\hline $\mathrm{Ni}$ & $2.62 \times 10^{-7}$ & $8.71 \times 10^{-11}$ & $3.08 \times 10^{-12}$ \\
\hline
\end{tabular}


All extraction constants were determined by a nonlinear least square method to fit the experimental results based on Eqs. (7) and (8) for cobalt and Eqs. (9) and (10) for nickel, respectively, and these values are summarized in Table 1. By using the obtained extraction constants, the free dimeric extractant concentrations can be calculated based on either Eq. (8) or Eq. (10), which enables determination of the distribution ratio at each equilibrium $\mathrm{pH}$. The calculated distribution ratios are shown as the lines in Figure 2. The extraction behavior of both cobalt and nickel are successfully expressed up to high loading ratios by the proposed extraction equilibrium formulations.

\subsection{Extraction of cobalt/nickel in the binary metal system}

Extraction equilibrium formulations determined in single metal system was then extended to extraction from the binary metal system. Figure 3 shows the effect of the equilibrium $\mathrm{pH}$ values on the loading ratios of cobalt and nickel, together with the calculated values based on the extraction equilibrium formulations determined in the single metal system assuming no interaction between the two metals. The experimental data are seen to cluster on the respective calculated lines, indicating the extraction equilibrium formulations obtained with the single metal system can be used in the binary metal system. In the binary metal system, selective extraction of cobalt took place, especially at lower extractant concentrations. Extraction of nickel was observed at high $\mathrm{pH}$ values, especially at higher extractant concentrations, and thus scrubbing of the organic phase after extraction is required to improve the purity of cobalt in the organic phase. Scrubbing of the organic phase after extraction of cobalt and nickel was then investigated. In this case, the organic phase after extraction of the metals was contacted with an aqueous scrubbing solution having a different $\mathrm{pH}$, i.e. a dilute sulfuric acid solution without metals. The resulting loading ratios are plotted in Figure 4 , together with the calculated values. The observed data are seen to cluster on the calculated values, indicating that scrubbing can also be expressed by the proposed extraction scheme. In addition, nickel extracted into the organic phase at the extraction step was effectively scrubbed off to the aqueous solution.
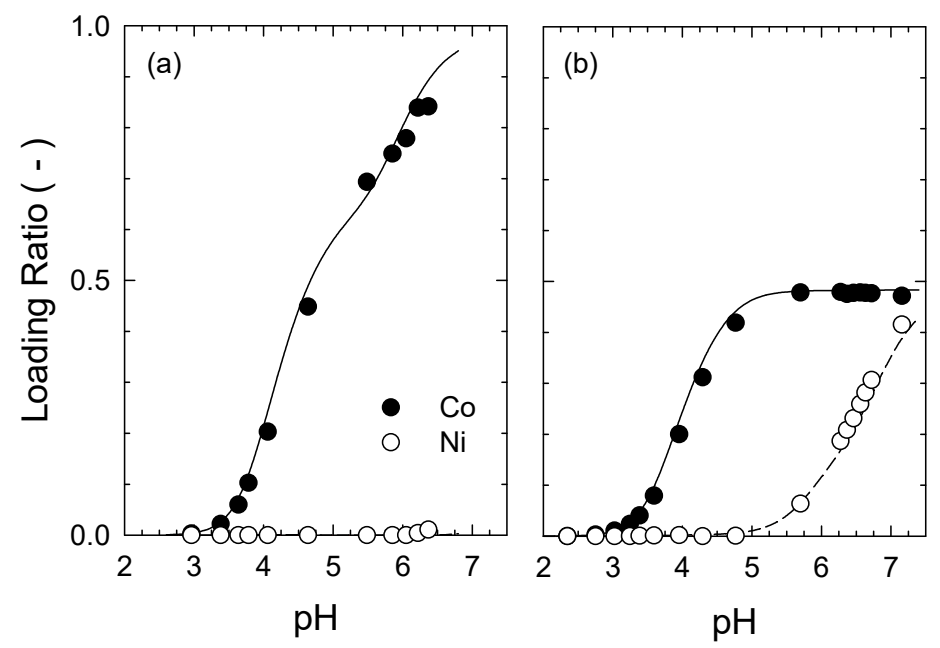

Figure 3. Effect of equilibrium $\mathrm{pH}$ on the loading ratios of cobalt and nickel. (a) $\left[\overline{(\mathrm{RH})_{2}}\right]_{\text {feed }}=4.98 \times 10^{-2}$ $\mathrm{mol} / \mathrm{L}$ and (b) $\left[\overline{(\mathrm{RH})_{2}}\right]_{\text {feed }}=1.02 \times 10^{-1} \mathrm{~mol} / \mathrm{L},[\mathrm{Co}]_{\text {feed }}=4.92 \times 10^{-2} \mathrm{~mol} / \mathrm{L}$, and $[\mathrm{Ni}]_{\text {feed }}=4.94 \times 10^{-2} \mathrm{~mol} / \mathrm{L}$. Calculated loading ratios are shown by the lines. 

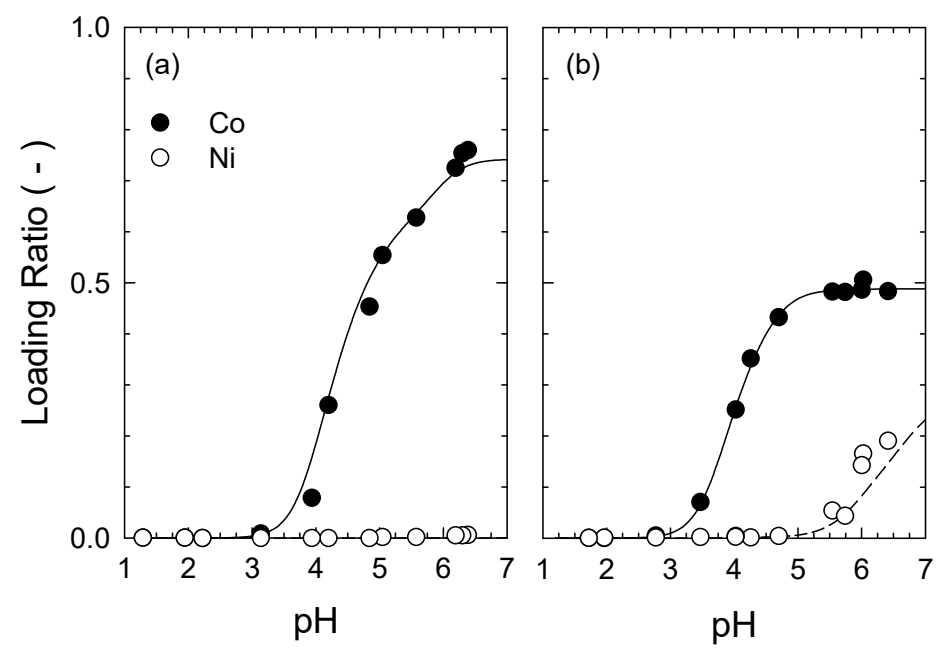

Figure 4. Effect of equilibrium $\mathrm{pH}$ on loading of cobalt and nickel after scrubbing of the organic phase.

(a) $\left[\overline{(\mathrm{RH})_{2}}\right]_{\text {feed }}=5.15 \times 10^{-2} \mathrm{~mol} / \mathrm{L},[\overline{\mathrm{Co}}]_{\text {org.feed }}=3.82 \times 10^{-2} \mathrm{~mol} / \mathrm{L}$, and $[\overline{\mathrm{Ni}}]_{\text {org.feed }}=6.31 \times 10^{-4} \mathrm{~mol} / \mathrm{L}$.

(b) $\left[\overline{(\mathrm{RH})_{2}}\right]_{\text {feed }}=1.02 \times 10^{-1} \mathrm{~mol} / \mathrm{L},[\overline{\mathrm{Co}}]_{\text {org,feed }}=4.97 \times 10^{-2} \mathrm{~mol} / \mathrm{L}$, and $[\overline{\mathrm{Ni}}]_{\text {org,feed }}=2.71 \times 10^{-2} \mathrm{~mol} / \mathrm{L}$.

Calculated loading ratios are shown by the lines.

\subsection{Separation of cobalt/nickel in the countercurrent mixer-settler cascade}

Separation of the metals using a 4-stage countercurrent mixer-settler cascade was then carried out. Figure 5 shows the schematic flowsheet for the countercurrent mixer- settler cascade. Firstly, the feed solution at $\mathrm{pH}=6.60$ was fed to the cascade. Concentration profiles of the metals in the aqueous and organic $\mathrm{p}$ hases, together with the $\mathrm{pH}$ at each stage, are shown in Figure 6. Although the $\mathrm{pH}$ of the aqueous solution was adjusted with a HEPES buffer solution, the $\mathrm{pH}$ dramatically decreased as the extraction progressed. The extraction yield of cobalt at the outlet of the organic phase (4th stage), defined as $[\overline{\mathrm{M}}]_{4} /[\mathrm{M}]_{\text {feed }}$, was $31.9 \%$, while that of nickel was $4.44 \%$. The concentration profiles of the metals were calculated based on the extraction equilibrium formulations already determined and the material balance [10-12]. In this case, the hydrogen ion concentration at each stage was not calculated, but the $\mathrm{pH}$ at each stage was fixed at the experimental value, since the $\mathrm{pH}$ was controlled by the buffer solution and thus the concentration of hydrogen ion at each stage was not able to be calculated with the extraction equilibrium formulations. The calculated results are also shown in Figure 6 as lines. The experimental

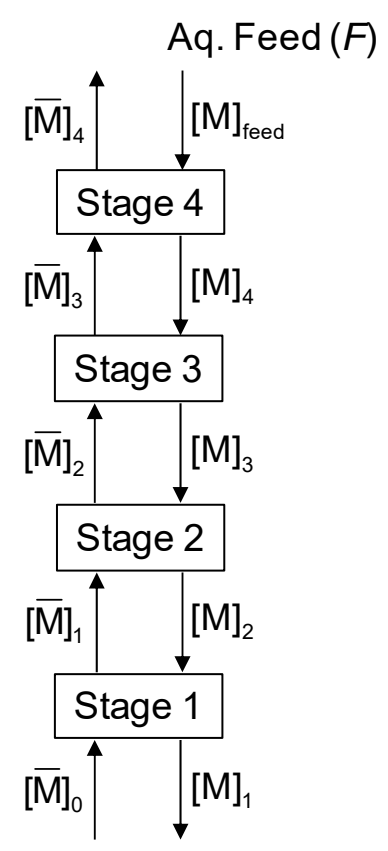

$\operatorname{Org}$. Feed $(E)$

Figure 5. Schematic flowsheet for the countercurrent mixer- settler cascade. 
concentrations of the metals in the organic phase were lower than those obtained by calculation. This is due to the stage efficiency of the countercurrent mixer-settler cascade. The stage efficiencies at each stage, defined as the ratio of the concentration of cobalt obtained from the experimental results to that obtained by the simulation work, were $43.3 \%$ (1st stage), 79.3\% (2nd stage), 59.4\% (3rd stage), and $75.6 \%$ (4th stage). The calculation method presented here is applicable for the prediction of the concentration profiles of the metals in the countercurrent mixer-settler cascade, when the stage efficiency is introduced in the calculation.
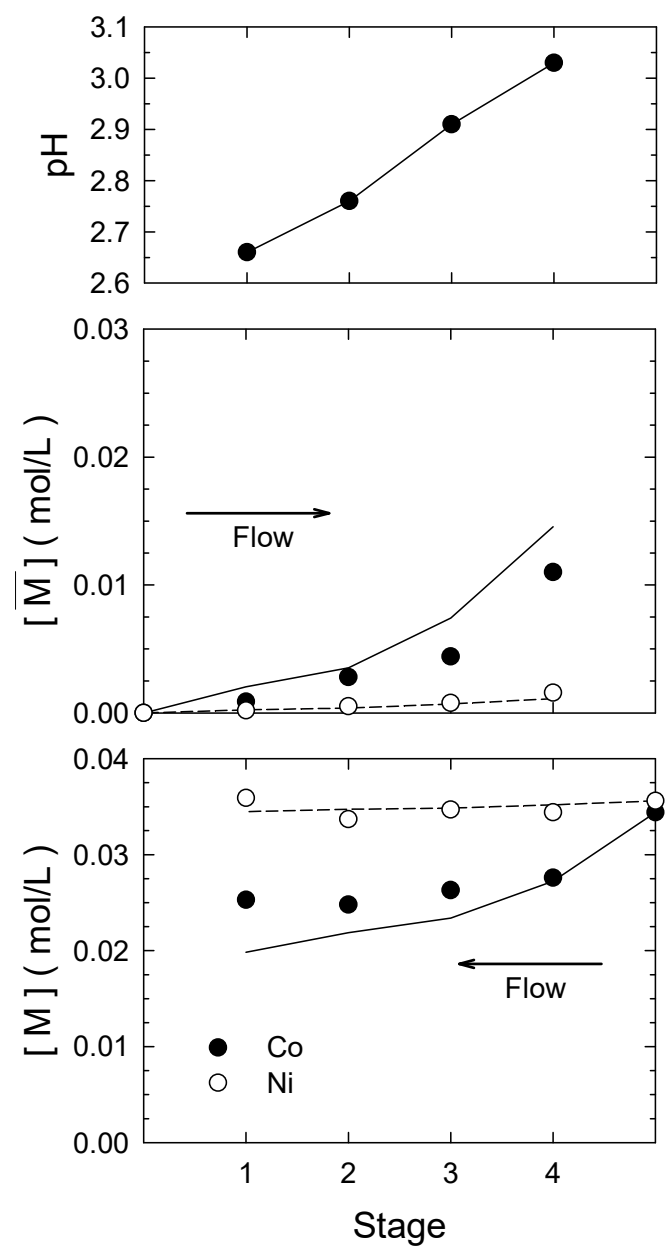

Figure 6. Concentration profile of cobalt and nickel in the 4-stage countercurrent mixer-settler cascade. $\left[\overline{(\mathrm{RH})_{2}}\right]_{\text {feed }}=5.04 \times 10^{-2} \mathrm{~mol} / \mathrm{L},[\mathrm{Co}]_{\text {feed }}=3.44 \times$ $10^{-2} \mathrm{~mol} / \mathrm{L},[\mathrm{Ni}]_{\text {feed }}=3.56 \times 10^{-2} \mathrm{~mol} / \mathrm{L}$, and $\mathrm{pH}_{\text {feed }}$ $=6.60$. Calculated concentration profiles are shown by the lines.
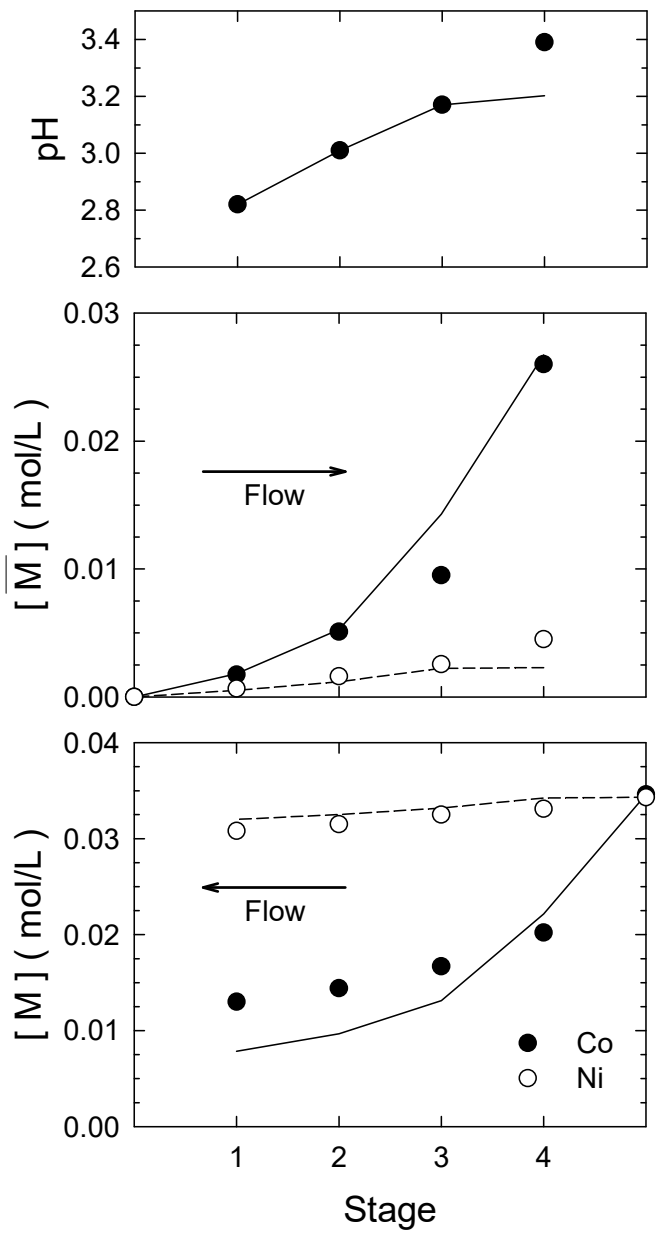

Figure 7. Concentration profile of cobalt and nickel in the 4-stage countercurrent mixer-settler cascade. $\left[\overline{(\mathrm{RH})_{2}}\right]_{\text {feed }}=5.24 \times 10^{-2} \mathrm{~mol} / \mathrm{L},[\mathrm{Co}]_{\text {feed }}=3.46 \times$ $10^{-2} \mathrm{~mol} / \mathrm{L},[\mathrm{Ni}]_{\text {feed }}=3.43 \times 10^{-2} \mathrm{~mol} / \mathrm{L}$, and $\mathrm{pH}_{\text {feed }}$ $=6.96$. Calculated concentration profiles are shown by the lines. 
Another experimental run was carried out wherein the $\mathrm{pH}$ of the feed solution was increased to 6.96 to improve extraction efficiency. The concentration profiles of the metals are shown in Figure 7. Selective extraction of cobalt was then achieved with an extraction yield of cobalt at the outlet of the organic phase (4th stage) of $75.1 \%$, while that of nickel was also slightly increased to $13.1 \%$. The purity of cobalt at the outlet of the organic phase was thus $85.2 \%$. The calculation of the mixer-settler cascade in this case was however not achieved, since the calculation was diverged by increasing the $\mathrm{pH}$, especially at the 4 th stage. The calculation result obtained for a $\mathrm{pH}$ value of 3.20 at the 4 th stage (experimental $\mathrm{pH}$ was 3.39) is shown in Figure 7.

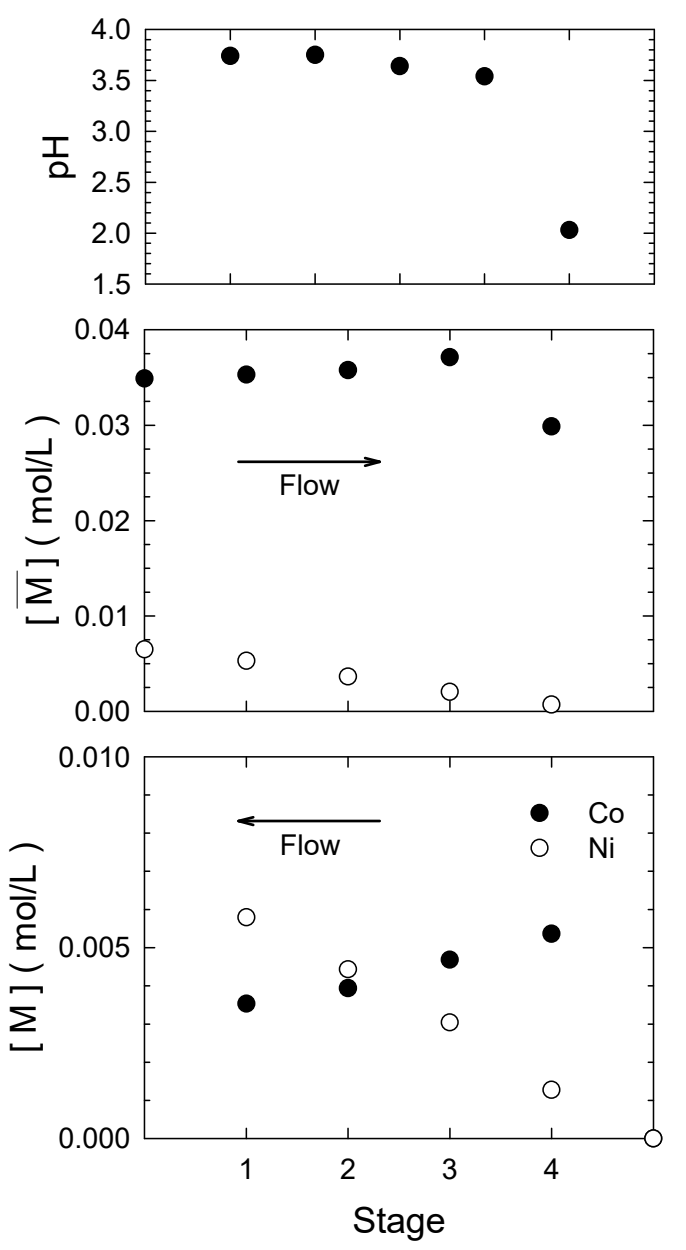

Figure 8. Concentration profile of cobalt and nickel in the 4-stage countercurrent mixer-settler cascade. $\left[\overline{(\mathrm{RH})_{2}}\right]_{\text {feed }}=4.96 \times 10^{-2} \mathrm{~mol} / \mathrm{L},[\overline{\mathrm{Co}}]_{\text {org,feed }}=3.49 \times$ $10^{-2} \mathrm{~mol} / \mathrm{L},[\overline{\mathrm{Ni}}]_{\text {org,feed }}=6.48 \times 10^{-3} \mathrm{~mol} / \mathrm{L}$, and $\mathrm{pH}_{\mathrm{sc}, \text { feed }}=2.03$.

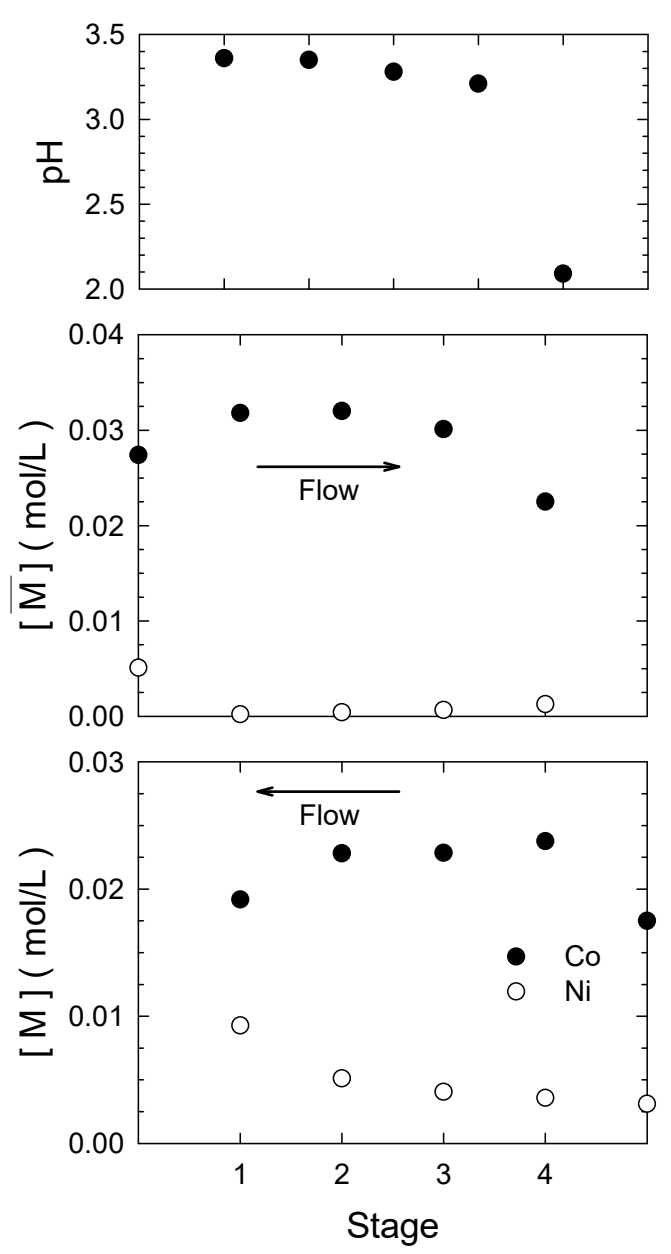

Figure 9. Concentration profile of cobalt and nickel in the 4-stage countercurrent mixer-settler cascade. $\left[\overline{(\mathrm{RH})_{2}}\right]_{\text {feed }}=4.91 \times 10^{-2} \mathrm{~mol} / \mathrm{L},[\overline{\mathrm{Co}}]_{\text {org,feed }}=2.74 \times$ $10^{-2} \mathrm{~mol} / \mathrm{L},[\overline{\mathrm{Ni}}]_{\text {org,feed }}=5.08 \times 10^{-3} \mathrm{~mol} / \mathrm{L}$, $[\mathrm{Co}]_{\mathrm{sc}, \text { feed }}=1.75 \times 10^{-2} \mathrm{~mol} / \mathrm{L},[\mathrm{Ni}]_{\mathrm{sc}, \text { feed }}=3.11 \times$ $10^{-3} \mathrm{~mol} / \mathrm{L}$, and $\mathrm{pH}_{\mathrm{sc}, \text { feed }}=2.03$. 


\subsection{Purification of cobalt using the countercurrent mixer-settler cascade}

Purification of the cobalt in the organic phase was investigated. In this case, extraction was carried out by a countercurrent mixer-settler cascade under the condition of Figure 7, and then the organic solution from the 4th stage was collected. The organic solution collected was then used as the organic feed solution for scrubbing with metal-free dilute sulfuric acid $\left(\mathrm{pH}_{\mathrm{sc}, \text { feed }}=2.03\right)$ using another countercurrent mixer-settler cascade. The concentration profile of the metals is shown in Figure 8. Nickel in the organic solution was gradually scrubbed off into the aqueous scrubbing solution, while a small amount of cobalt was also stripped. The purity of the cobalt in the organic solution at the outlet of the organic phase (4th stage) was now $97.7 \%$, with a recovery yield of cobalt at the scrubbing step, defined as $[\overline{\mathrm{Co}}]_{4, \text { scrubbing }} /[\overline{\mathrm{Co}}]_{0, \text { scrubbing }}$, of $85.6 \%$.

Scrubbing with an aqueous solution containing metals was then carried out. The concentration profile of the metals is shown in Figure 9. In this case, removal of nickel into the aqueous scrubbing solution was enhanced due to displacement between nickel in the organic solution and cobalt in the aqueous scrubbing solution. The purity of cobalt in the organic solution at the outlet of the organic phase (4th stage) was improved to $99.1 \%$. However, since a part of the cobalt in the scrubbing solution remained in the aqueous phase, the recovery yield of cobalt at the scrubbing step, defined as $[\overline{\mathrm{Co}}]_{4, \text { scrubbing }} /\left([\overline{\mathrm{Co}}]_{0, \text { scrubbing }}+[\mathrm{Co}]_{\text {fed,scrubbing }}\right)$, decreased to $50.0 \%$. Optimization of the $\mathrm{pH}$ in the scrubbing step is therefore required to improve both purity and recovery yields.

\section{Conclusion}

We described separation of cobalt and nickel with PC-88A using a 4-stage countercurrent mixer-settler cascade. The important features are summarized as follows. The extraction equilibrium formulations of cobalt and nickel with PC-88A were determined up to high loading ratios in single metal systems, and were applicable for both extraction and scrubbing in the binary metal system. Selective extraction of cobalt was achieved in the cascade, while a small amount of nickel was also extracted. The extracted nickel was successfully removed by scrubbing with an aqueous solution containing the metals. The concentration profiles of the metals in the cascade was calculated based on the extraction equilibrium formulations determined and the material balance, although the calculation diverged at high $\mathrm{pH}$ values. The calculation method was thus applicable to predict the concentration profiles of the metals by introducing the stage efficiencies.

\section{Acknowledgement}

The authors are grateful to Professor Junji Shibata of Kansai University for manufacturing the countercurrent mixer-settler cascade.

\section{References}

1) I. Komasawa, T. Otake, Y. Higaki, J. Inorg. Nucl. Chem., 43, 3351-3355 (1981).

2) I. Komasawa, T. Otake, I. Hattori, J. Chem. Eng. Japan, 16, 210-217 (1983).

3) P.R. Danesi, L. Reichley-Yinger, G. Mason, L. Kaplan, E.P. Horwitz, H. Diamond, Solvent Extr. Ion 
Exch., 3, 435-452 (1985).

4) C. Yuan, Q. Xu, S. Yuan, H. long, D. Shen, Y. Jiang, H. Feng, F. Wu, W. Chen, Solvent Extr. Ion Exch., 6, 393-416 (1988).

5) T. Takahashi, T. Sato, Shigen-to-Sozai, 111, 787-792 (1995).

6) Y. Pranolo, W. Zhang, C.Y. Cheng, Hydrometallurgy, 102, 37-42 (2010).

7) F. Wang, R. Sun, J. Xu, Z. Chen, M. Kang, RSC Adv., 6, 85303-85311 (2016).

8) S.H. Joo, D.J. Shin, C.H. Oh, J.P. Wang, G. Senanayake, S.M. Shin, Hydrometallurgy, 159, 65-74 (2016)

9) A. Chagnes, B. Pospiech, J. Chem. Technol. Biotechnol., 88, 1191-1199 (2013).

10) A. Hino, S. Nishihama, T. Hirai, I. Komasawa, J. Chem. Eng. Japan, 30, 1040-1046 (1997).

11) S. Nishihama, T. Hirai, I. Komasawa, Ind. Eng. Chem. Res., 38, 1032-1039 (1999).

12) S. Nishihama, T. Hirai, I. Komasawa, Ind. Eng. Chem. Res., 39, 3907-3911 (2000).

13) N.V. Thakur, S.L. Mishra, Hydrometallurgy, 48, 277-289 (1998). 